\title{
Normal weight obesity and physical fitness in Chinese university students: an overlooked association
}

\author{
Meizhen Zhang ${ }^{1,2,3 \dagger}$, Moritz Schumann $^{1,4 \dagger}$, Tao Huang $^{\text {* }^{*} \text { (D) Timo Törmäkangas }}{ }^{5}$ and Sulin Cheng ${ }^{1,6,7}$
}

\begin{abstract}
Background: The primary aim of this study was to examine the associations of normal weight obesity (NWO) with physical fitness in Chinese university students. As a secondary aim, we assessed whether possible differences in physical fitness between students classified as NWO and normal weight non-obese (NWNO) were mediated by skeletal muscles mass.

Methods: A total of 383 students (205 males and 178 females, aged 18-24 years) from two universities volunteered to participate in this study. Body height and weight were measured by standard procedures and body composition was assessed by bio-impedance analysis (InBody 720). NWO was defined by a BMI of $18.5-23.9 \mathrm{~kg} / \mathrm{m}^{2}$ and a body fat percentage of $>20 \%$ or $>30 \%$ in male and female students, respectively. Physical fitness was measured using a 10-min intermittent endurance running test (Andersen test), countermovement jumps (CMJ) and a $5 \times 5 \mathrm{~m}$ shuttle run test ( $5 \mathrm{mSR})$. The level of leisure time physical activity (PA) was assessed by a questionnaire.
\end{abstract}

Results: $13.7 \%$ of male and $27.5 \%$ of female students were classified as NWO. Compared to NWNO, students classified as NWO showed a significantly poorer performance in the Andersen test (males: $1146 \pm 70 \mathrm{~m}$ vs. $1046 \pm$ $95 \mathrm{~m}$, females: $968 \pm 61 \mathrm{~m}$ vs. $907 \pm 67 \mathrm{~m}, p<0.001$ ), CMJ (males: $55.0 \pm 7.6 \mathrm{~cm}$ vs. $44.9 \pm 7.5 \mathrm{~cm}$, females: $39.8 \pm 8.0$ $\mathrm{cm}$ vs. $33.7 \pm 5.9 \mathrm{~cm}, p<0.001$ ) and $5 \mathrm{mSR}$ (males: $18.7 \pm 1.0 \mathrm{~s}$ vs. $20.0 \pm 0.9 \mathrm{~s}$, females: $21.1 \pm 1.1 \mathrm{~s}$ vs. $22.4 \pm 1.3 \mathrm{~s}, p<$ 0.001 ), respectively. The lower levels of physical fitness in NWO were partially explained by lower skeletal muscle mass $(p<0.001)$ both in male and female students.

Conclusions: NWO was associated with poorer physical fitness and the relationship was partially mediated by lower skeletal muscle mass. The study indicated that attention should be paid for the potential hidden health risk in university students with normal body mass index but excessive fat mass.

Keywords: Body-mass index, Body composition, Skeletal muscle mass, Physical activity, Public health

\section{Background}

The prevalence of obesity is nowadays one of the most severe health concerns worldwide, due to the often observed complications, such as diabetes and cardiovascular diseases [1-3]. In China, the prevalence of overweight and obesity has dramatically increased in adults [4], while levels of physical fitness have decreased over the past years [5].

Typically, obesity has been classified by means of the body mass index (BMI), due to its simplicity and

\footnotetext{
* Correspondence: taohuang@sjtu.edu.cn

${ }^{\dagger}$ Meizhen Zhang and Moritz Schumann contributed equally to this work.

'Department of Physical Education, Exercise, Health and Technology Centre,

Shanghai Jiao Tong University, Shanghai 200240, China

Full list of author information is available at the end of the article
}

validation in multiple epidemiologic studies [6]. However, it has previously been shown that a quarter of children with excess body fat percentage were misdiagnosed solely based on BMI [7]. This might be especially due to the BMI not allowing to distinguish between fat and lean tissue, particularly in individuals with a $\mathrm{BMI} \leq 30 \mathrm{~kg} / \mathrm{m}^{2}$ but excessive body fat [8-11]. Interestingly, individuals with a normal BMI but a high percentage of body fat $(>20 \%$ in men and $>30 \%$ in women, respectively) bear an increased risk for systemic inflammation, metabolic dysregulation, and mortality [12]. This condition is commonly referred to as normal weight obesity (NWO) $[12,13]$.

(c) The Author(s). 2018 Open Access This article is distributed under the terms of the Creative Commons Attribution 4.0 International License (http://creativecommons.org/licenses/by/4.0/), which permits unrestricted use, distribution, and 
However, the potential influence of NWO on health-related physical fitness is not well studied. In fact, physical fitness is considered one of the most important health markers and commonly understood as a predictor of morbidity and mortality for cardiovascular diseases [14, 15]. As such, numerous studies have shown that a high BMI and/or obesity are associated with poor physical fitness due to the higher body fat and lower skeletal muscle mass [16-19]. Moreover, both skeletal muscle mass and strength might be closely associated with cardiorespiratory fitness $[20,21]$ and health [22], providing reasoning to assume that skeletal muscle may mediate the relationship between NWO and physical fitness.

Consequently, gaining a better understanding of the risk factors that are associated with normal weight obesity is an important step towards designing interventions and making policies to promote healthy lifestyles in young adults. The primary aim of this study was to examine the associations of physical fitness with NWO in Chinese university students. As a secondary objective, we aimed to assess whether possible differences in physical fitness between students classified as NWO and normal weight non-obese (NWNO) are mediated by skeletal muscles mass. We hypothesized that NWO is associated with poorer physical fitness both in male and female students. In addition, it was postulated that the differences in physical fitness between NWO and NWNO groups are mediated by skeletal muscles mass.

\section{Methods}

\section{Subjects}

A total of 383 students (205 males and 178 females) aged 18-24 years were recruited from two universities in China during September 2015 to July 2017 to participate in the study. The data collection was carried out during the same period. All participants provided written informed consents prior to the tests and the study was approved by the Institutional Review Board of Shanghai Jiao Tong University (M15018).

\section{Anthropometrics and body composition}

Body height was measured to the nearest $0.1 \mathrm{~cm}$ using a wall-mounted height scale. Body weight, total fat, visceral fat area and skeletal muscle mass were measured after emptying the bladder and in light underwear using a calibrated InBody 720 bio-impedance device (Biospace, Co, Ltd., Seoul, Korea) [23, 24]. All participants received similar instructions prior to the assessment of body composition and were required to be in a fasted state. Waist circumference was measured twice to the nearest $0.1 \mathrm{~cm}$ (or three times if a discrepancy of more than 3 $\mathrm{cm}$ was observed) at the midpoint between the lower costal margin and the level of the anterior superior iliac crests, by a flexible measuring tape.
BMI is calculated as the body mass $(\mathrm{kg})$ divided by the square of the body height $(\mathrm{m})$. Based on the BMI value, the participants were categorized into the three following groups: underweight $\left(\mathrm{BMI}<18.5 \mathrm{~kg} / \mathrm{m}^{2}\right)$, normal weight $\left(18.5 \leq \mathrm{BMI} \leq 23.9 \mathrm{~kg} / \mathrm{m}^{2}\right)$ and overweight $(\mathrm{BMI} \geq$ $24 \mathrm{~kg} / \mathrm{m}^{2}$ ) [25]. According to the cut-off points of body fat percentage (i.e. $20 \%$ for men and $30 \%$ for women) [13], the normal weight group was further divided into a normal weight obesity and normal weight non-obese (NWNO) group.

\section{Self-reported physical activity}

Daily physical activity was assessed by the Chinese version of the Physical Activity Questionnaire [26], which included information about the frequency, duration and intensity of each physical activity per week.

\section{Physical fitness}

In order to allow for familiarization with all testing procedures, all participants received oral instructions and demonstrations for all physical fitness tests prior to the evaluation.

\section{Cardiovascular fitness}

Initially, resting systolic and diastolic blood pressure (SBP \& DBP) were measured in a seated position by an Electronic sphygmomanometer (OMRON HEM 7051, Dalian, Liaoning, China). The measurement was performed twice at the interval of 2 min by a trained researcher. The mean of the two measures was used for statistical analysis.

Thereafter, a 10-min intermittent shuttle run test (Andersen test) [27] was performed to estimate cardiovascular fitness. During this test, the participants alternate between running and standing for $15 \mathrm{~s}$ at a time. The participants were required to cover as much distance as possible for $5 \mathrm{~min}$ [27]. The total running distance covered was used for statistical analysis.

\section{Muscular power}

Muscular power of the lower extremities was assessed by a countermovement jump (CMJ) with arm swing [28, 29]. The test was repeated 3 times at interval for $2 \mathrm{~min}$. Jumping height was assessed by a flexible measuring tape attached to the level of the 4-5th lumbar vertebra. After correctly preparing the equipment, the participants were firstly instructed to squat and jump as quickly and high as possible using the arms. The difference between the initial and final values of the ruler at the junction of the belt and ground tape was used to determine jumping height. The average jump height of all 3 trials was used for statistical analysis. 


\section{Speed and agility}

Speed and agility were assessed by a $5 \times 5 \mathrm{~m}$ shuttle run test $(5 \mathrm{mSR})[30,31]$. During this test, the participants were requested to alternate with maximal movement velocity between two lines, each $5 \mathrm{~m}$ apart. Participants were required to cross both lines entirely with their feet, while back and forth lap was counted as one lap. This was repeated 5 times without rest. The total time of the best completed set of laps was used for statistical analysis.

Based on the results of all three tests, we also generated a gender-specific composite physical fitness score, defined as the sum of the standardized values (z-score) of all three tests $[32,33]$.

\section{Statistical analysis}

All statistical analyses were performed separated by gender. Normality of the data was checked by calculating skewness and kurtosis and also tested by the Kolmogorov-Smirnov test. Baseline characteristics were presented using means and standard deviations. Weight-group differences in baseline characteristics were assessed using independent T-tests. In addition, analysis of covariance (ANCOVA) was used to examine the between-group differences on physical fitness with adjustment for age and physical activity. These analyses were performed using SPSS 22.0 (SPSS Inc., Chicago, IL, USA) with a two-sided significance level of 0.05 .

Mediation analyses were conducted in order to assess whether skeletal muscle mass mediated the relationship between weight group and physical fitness (Andersen test, CMJ, 5mSR, sum of physical fitness), adjusted for age and physical activity. The mediation analysis was conducted by Mplus version 7 (Muthén \& Muthén, Los Angeles, CA, USA). As shown in Fig. 1, in the mediation models weight group (NWO vs. NWNO) was considered as an independent variable, while body height-adjusted skeletal muscle mass $(\mathrm{SMM} / \mathrm{BH})$ used as the mediator

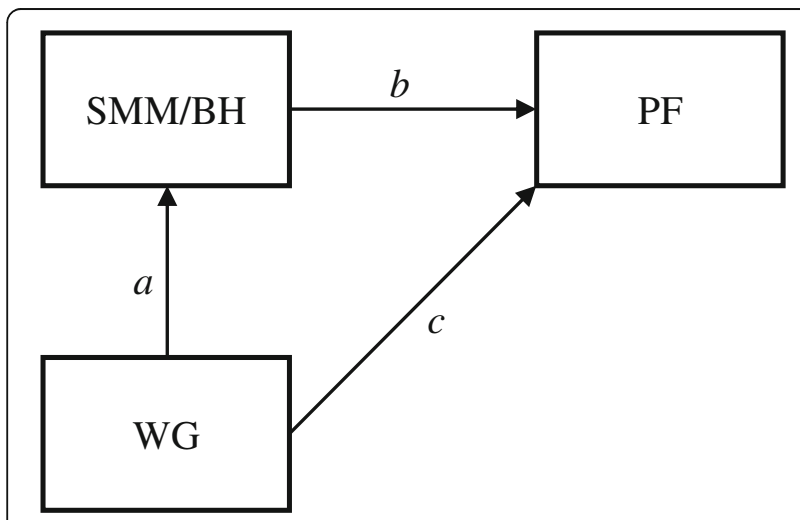

Fig. 1 Conceptual model of the mediation analysis. (a representing the effect of weight group (WG) on body height-adjusted skeletal muscle mass $(\mathrm{SMM} / \mathrm{BH}), b$ the effect of SMM/BH on physical fitness $(\mathrm{PF})$, and $c$ the effect of weight group on physical fitness (PF)) variable and measures of physical fitness (Andersen test, CMJ, 5mSR, sum of physical fitness) were treated as dependent variables. According to Imai [34] and Loeys [35], the following criteria must be met to establish mediation effects. First, the independent variable must significantly influence the mediator; second, the independent variable must significantly influence the dependent variable; third, the mediator must significantly influence the dependent variable. Further, if the effect of the independent variable on the dependent variable (i.e. direct effect) entirely diminishes when the mediator is included in the model, the mediator fully mediates between independent and dependent variables (full mediation). If the effect of the independent variable on the dependent variable remains with a smaller magnitude when the mediator is included in the model, the mediator partially mediates between independent and dependent variables (partial mediation) [36]. Direct, indirect and total effects from the models as well as the proportion of variance of the physical performance variables explained by the model were reported. The proportion of effect mediation was calculated by the equation $=100$ * indirect effect / total effect [36].

\section{Results}

\section{Participants' characteristics}

Out of the 383 participants, $14.1 \%$ of males and $36.0 \%$ of females were classified as underweight, and $61.0 \%$ and $59.5 \%$ as normal weight, respectively. In addition, $24.9 \%$ of males and $4.5 \%$ of females were classified as overweight. Of the participants who were classified as normal weight, $47.3 \%$ of males and $32.0 \%$ of females were classified as NWNO, while $13.7 \%$ of males and $27.5 \%$ of females were NWO. The characteristics of all the participants are shown in Additional file 1: Table S1. For the purpose of the present study, the analyses were restricted to the NWO and NWNO groups.

The participants' characteristics of NWO and NWNO are shown in Table 1. Most of the anthropometric and physical characteristics differed significantly between genders (all $p<0.05)$, except for age $(p=0.20)$ and diastolic blood pressure $(p=0.47)$. No significant difference was observed between NWO and NWNO in body weight and heart rate in both genders and physical activity in male students (all $p>0.05$ ). Age, waist circumference, visceral fat area, body fat percentage and BMI were significantly higher in NWO compared to NWNO both in male and female students (all $p<0.05$ ) and physical activity only in females $(p=0.03)$. Body height and skeletal muscle mass were significantly lower in NWO than NWNO for both genders (all $p<0.05$ ). Furthermore, DBP and SBP were significantly higher in NWO compared to NWNO only in females (all $p<0.001$ ). 
Table 1 Participants characteristics stratified by gender and weight group (Mean \pm SD)

\begin{tabular}{|c|c|c|c|c|}
\hline \multirow[t]{2}{*}{ Variables } & \multicolumn{2}{|l|}{ Men $(n=125)$} & \multicolumn{2}{|l|}{ Women $(n=106)$} \\
\hline & NWNO $(n=97)$ & NWO $(n=28)$ & NWNO $(n=57)$ & NWO $(n=49)$ \\
\hline Age (year) & $20.2 \pm 1.4^{*}$ & $20.9 \pm 1.8$ & $19.7 \pm 1.6^{* *}$ & $20.6 \pm 1.5$ \\
\hline $\mathrm{BH}(\mathrm{cm})$ & $175.8 \pm 6.5^{* *}$ & $171.5 \pm 6.8$ & $162.9 \pm 6.2^{*}$ & $160.0 \pm 5.1$ \\
\hline BW (Kg) & $65.3 \pm 6.6$ & $66.1 \pm 6.2$ & $53.9 \pm 5.5$ & $55.5 \pm 4.6$ \\
\hline WC (cm) & $75.0 \pm 4.4^{* *}$ & $79.7 \pm 4.0$ & $68.1 \pm 4.4^{* *}$ & $73.2 \pm 4.5$ \\
\hline VFA $\left(\mathrm{cm}^{2}\right)$ & $28.5 \pm 13.7^{* *}$ & $59.7 \pm 13.3$ & $52.4 \pm 9.1^{* *}$ & $73.2 \pm 14.3$ \\
\hline Fat $\%$ & $12.3 \pm 3.8^{* *}$ & $23.1 \pm 3.4$ & $24.4 \pm 2.6^{* *}$ & $32.1 \pm 2.3$ \\
\hline $\mathrm{BMI}\left(\mathrm{kg} / \mathrm{m}^{2}\right)$ & $21.1 \pm 1.4^{* *}$ & $22.5 \pm 1.2$ & $20.3 \pm 1.3^{* *}$ & $21.7 \pm 1.3$ \\
\hline $\mathrm{SMM} / \mathrm{BH}(\mathrm{Kg} / \mathrm{m})$ & $18.3 \pm 1.5^{* *}$ & $16.5 \pm 1.5$ & $13.5 \pm 1.1^{* *}$ & $12.6 \pm 0.9$ \\
\hline $\mathrm{DBP}(\mathrm{mmHg})$ & $69.5 \pm 7.0$ & $71.9 \pm 8.8$ & $66.9 \pm 6.1^{* *}$ & $72.1 \pm 8.4$ \\
\hline $\mathrm{SBP}(\mathrm{mmHg})$ & $120.4 \pm 9.5$ & $119.6 \pm 10.0$ & $104.9 \pm 8.3^{* *}$ & $112.3 \pm 10.7$ \\
\hline $\mathrm{HR}$ & $72.7 \pm 9.8$ & $73.7 \pm 12.5$ & $75.5 \pm 9.4$ & $75.8 \pm 9.7$ \\
\hline PA (Mets*H/wk) & $30.4 \pm 10.4$ & $27.8 \pm 13.1$ & $21.7 \pm 8.6^{*}$ & $27.5 \pm 15.3$ \\
\hline
\end{tabular}

Abbreviations: NWNO Normal weight non-obese, NWO Normal weight obesity

$B H$ Body height, $B W$ Body weight, WC Waist circumference, VFA Visceral fat area, Fat\% Body fat percentage, $B M I$ Body mass index, SMM Skeletal muscle mass, DBP Diastolic blood pressure, SBP Systolic blood pressure, HR Heart rate, PA Physical activity;

*Indicates $p<0.05$ (NWNO vs. NWO)

**Indicates $p<0.01$ (NWNO vs. NWO)

\section{Differences in physical fitness between NWO and NWNO}

After adjustment for age and physical activity, significant differences were observed between groups in all three measures of physical fitness. The three physical fitness measures were similar between NWO and overweight (OW) groups (Additional file 1: Table S1). However, compared to NWNO, participants classified as NWO showed a poorer performance in the Andersen test (males: $1146 \pm$ $70 \mathrm{~m}$ vs. $1046 \pm 95 \mathrm{~m}$, females: $968 \pm 61 \mathrm{~m}$ vs. $907 \pm 67 \mathrm{~m}$, $p<0.001$ ), CMJ (males: $55 \pm 7.6 \mathrm{~cm}$ vs. $44.9 \pm 7.5 \mathrm{~cm}$, females: $39.8 \pm 8.0 \mathrm{~cm}$ vs. $33.7 \pm 5.9 \mathrm{~cm}, p<0.001)$ and $5 \mathrm{mSR}$ (males: $18.7 \pm 1.0 \mathrm{~s}$ vs. $20.0 \pm 0.9$ s, females: $21.1 \pm$ $1.1 \mathrm{~s}$ vs. $22.4 \pm 1.3 \mathrm{~s}, p<0.001$ ), as well as in the sum of the physical fitness score (males: $0.8 \pm 1.7$ vs. $-2.6 \pm 1.9$, females: $1.3 \pm 1.6$ vs. $-1.3 \pm 1.7, p<0.001$ ), respectively (Figs. 2, 3, 4 and 5).

\section{Results of the mediation analyses}

Our study fulfilled the three criteria for significant mediation effects between 1) weight group and each outcome, 2 ) weight group and skeletal muscle mass, and 3) weight group and skeletal muscle mass predicting each outcome, as well as the effect modification of weight group from model 1) to 3) in the appropriate direction (i.e. the weight group had a lower effect in model 3) for all cases except CMJ among girls. The path coefficients of direct,

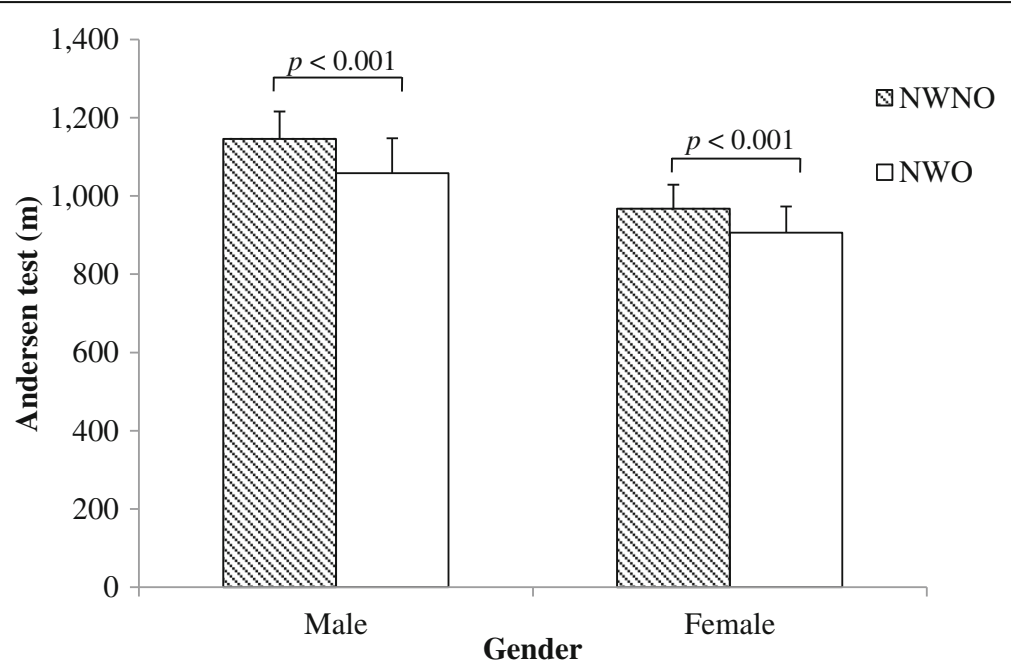

Fig. 2 Distance covered during the Andersen Test in NWO and NWNO 


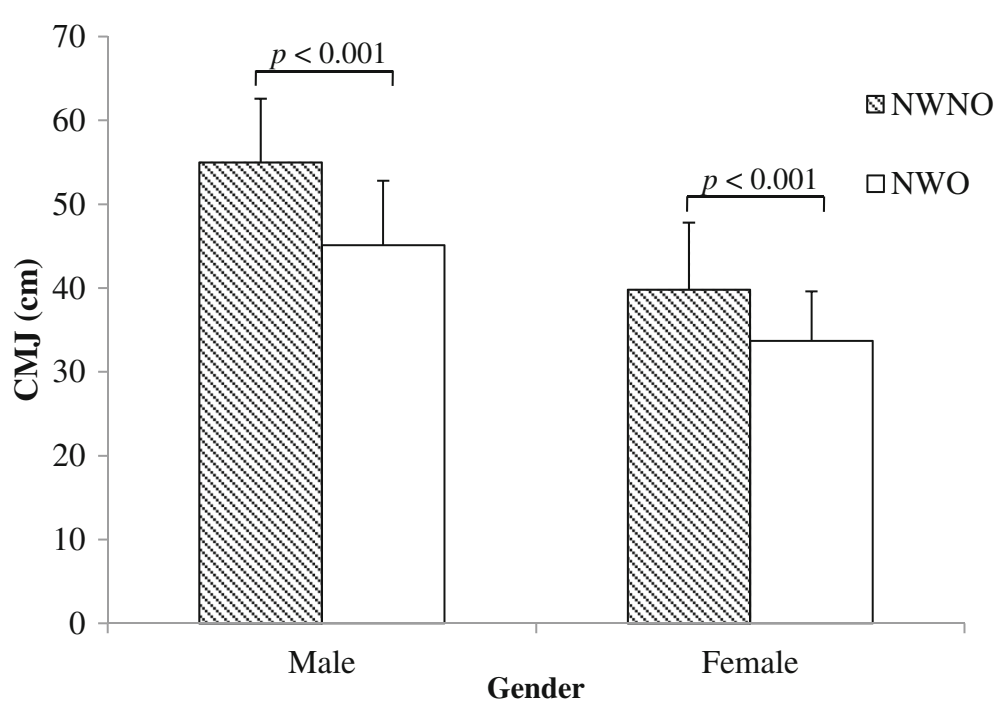

Fig. 3 Countermovement jumping (CMJ) height in NWO and NWNO

indirect and total effects of the mediation models are shown in Table 2. For cardiovascular fitness, there was an indirect effect of weight group on performance in the Andersen test through skeletal muscle mass both in male $(p<0.01)$ and female students $(p<$ 0.05 , proportion of mediation: men 27\%, women $23 \%)$. The direct effect of weight group was also significant $(p<0.001)$, indicating that skeletal muscle mass partially mediated the negative relationship between the body weight group and cardiovascular fitness in both male and female students. Similarly, also in speed and agility an indirect effect of the weight group on performance in the $5 \mathrm{mSR}$ test through skeletal muscle mass was observed both in male and female students $(p<0.01$, proportion of mediation: men $24 \%$, women $23 \%$ ). The direct effect of weight group on $5 \mathrm{mSR}$ performance was also significant $(p<0.001)$, which indicated that skeletal muscle mass partially mediated the negative relationship between body weight group and speed and agility in male and female students.

There was an indirect effect of weight group on performance in CMJ test through skeletal muscle mass only in male students $(p=0.002$, proportion of mediation: $28 \%$ ). The direct effect of weight group was also significant $(p<0.001)$, indicating that skeletal muscle mass partially mediated the negative relationship between the body weight group and muscular power in male students.

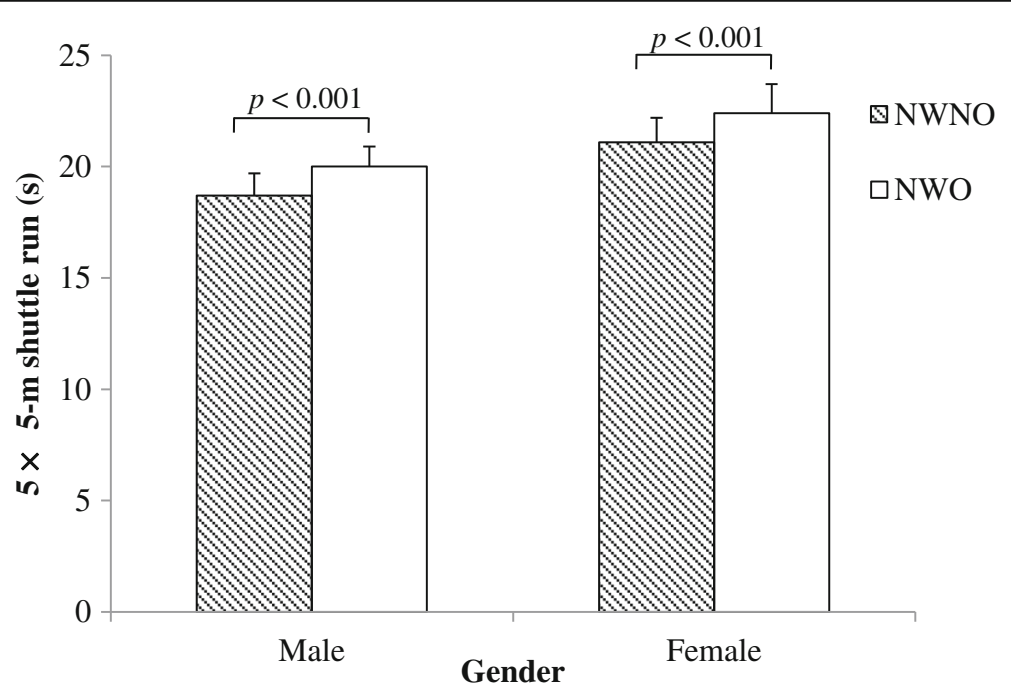

Fig. 4 Time needed to cover the $5 \times 5$-m shuttle run test in NWO and NWNO 


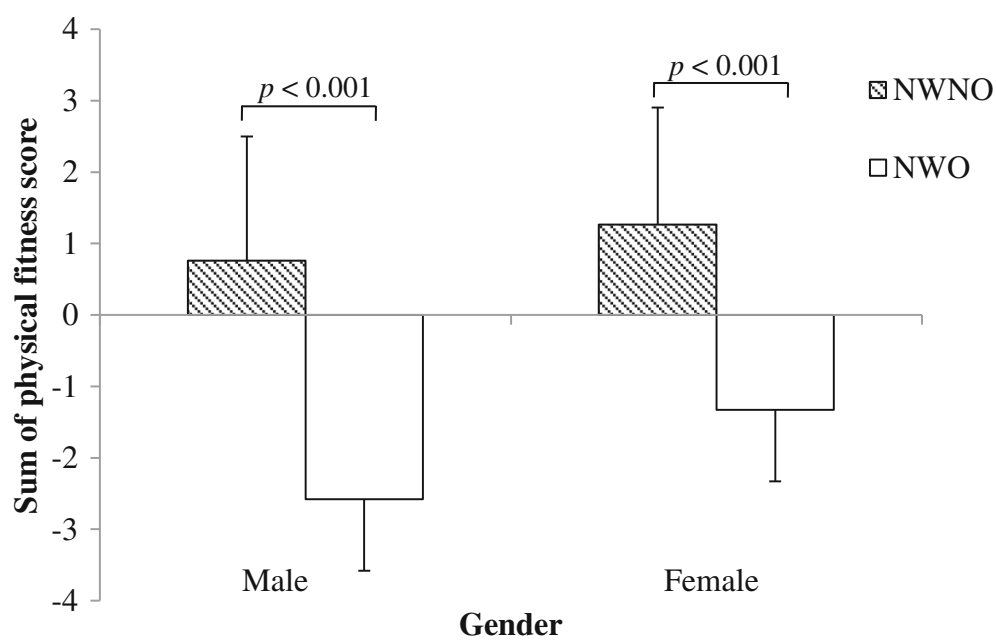

Fig. 5 Sum of physical fitness score in NWO and NWNO

For the sum score of physical fitness, the indirect and direct effects were both statistically significant in male and female students (all $p<0.01$, proportion mediation: male $24 \%$, female $21 \%$ ), which indicates that the negative relationship between body weight group and physical fitness was partially mediated by skeletal muscle mass. Thus, the NWO university students tended to have less skeletal muscle mass, which might partly contribute to the observed decreased physical fitness.

\section{Discussion}

The primary findings of the study were that $13.7 \%$ of the male and $27.5 \%$ of the female students were classified as NWO and these students were characterized by lower levels of physical fitness compared with their NWNO peers. Furthermore, we found that low levels of physical fitness (SumPF, Andersen test, 5mSR) in NWO were partially mediated by a lower skeletal muscle mass in both males and females. For CMJ, however, the mediation role of skeletal muscle mass was observed only in male students.

The high prevalence of NWO in both male and female students was in contrast to a Swiss study in adults (aged 35-75 years), which showed a much lower prevalence of NWO of only $5.4 \%$ in women and less than $3 \%$ in men [37]. However, in a Finnish study of young women (mean age $=18$ years), the prevalence of NWO was estimated to be $39.0 \%[38,39]$. Our results concerning the prevalence of NWO in women were similar to a study of normal weight central obesity in South Africa [40]. The differences among these studies are somewhat interesting but it should be noted that the results cannot be directly compared, since to the best of our knowledge, our study is the first to investigate the prevalence of NWO among Chinese university students. The large discrepancy between studies may be attributed to the differences in the assessment methods used and participant characteristics such as age, dietary characteristics, lifestyle, and ethnicity. Despite these differences between the present study and previous investigations, our results indicated a potential hidden health threat by which nearly every eighth male and especially every third female student in China could be classified as normal weight obese.

Previous studies have shown that NWO is associated with metabolic disorders [37, 41], an increased risk of the metabolic syndrome [42] and cardiovascular diseases, as well as an increase in all-cause mortality [43]. However, little is known about the association of NWO with physical fitness. The findings of the current study extend to previous work by showing that young adults with a normal BMI but excessive body fat mass performed worse on the three measures of physical fitness. Since lower physical fitness is a predictor of chronic diseases [44], the findings of the current study are clinically important. Thus, students classified as NWO should not only follow standard physical activity recommendations but should also target on progressive muscular strength training to improve physical fitness and prevent further potential health risks. Importantly, although the current study focused on the NWO in young adults, this may not necessarily mean that the established health risks of overweight and obesity can be neglected. However, given the potential influence of NWO on physical fitness, the findings of our study highlight the importance of considering body composition analysis rather than only measuring BMI in future preventive studies and practices.

In order to clarify the roles of skeletal muscle mass on the relationship between NWO and physical fitness, we further conducted a series of mediation analyses and found that NWO had a negative influence on skeletal 
Table 2 Standardized effects of the mediation models by gender

\begin{tabular}{|c|c|c|c|c|c|c|c|}
\hline Model (male) & Path coefficients & $95 \% \mathrm{Cl}$ & $p$-value & Model (female) & Path coefficients & $95 \% \mathrm{Cl}$ & $p$-value \\
\hline Andersen test (A) & & & & Andersen test (A) & & & \\
\hline Direct effects & & & & Direct effects & & & \\
\hline WG $\rightarrow$ SMM (a) & -0.46 & $-0.60 \sim-0.32$ & $<0.001$ & WG $\rightarrow \operatorname{SMM~(a)~}$ & -0.38 & $-0.54 \sim-0.22$ & $<0.001$ \\
\hline $\mathrm{SMM} \rightarrow \mathrm{A}(b)$ & 0.28 & $0.10 \sim 0.45$ & 0.002 & $\mathrm{SMM} \rightarrow \mathrm{A}(b)$ & 0.25 & $0.06 \sim 0.45$ & 0.012 \\
\hline $\mathrm{WG} \rightarrow \mathrm{A}(\mathrm{c})$ & -0.36 & $-0.53 \sim-0.19$ & $<0.001$ & $\mathrm{WG} \rightarrow \mathrm{A}(\mathrm{c})$ & -0.33 & $-0.53 \sim-0.14$ & 0.001 \\
\hline Indirect effects & & & & Indirect effects & & & \\
\hline $\mathrm{WG} \rightarrow \mathrm{A}(a \times b)$ & -0.13 & $-0.22 \sim-0.04$ & 0.006 & $\mathrm{WG} \rightarrow \mathrm{A}(a \times b)$ & -0.10 & $-0.18 \sim-0.01$ & 0.029 \\
\hline Total effect & & & & Total effect & & & \\
\hline$W G \rightarrow A(a \times b+c)$ & -0.49 & $-0.63 \sim-0.34$ & $<0.001$ & $\mathrm{WG} \rightarrow \mathrm{A}(a \times b+c)$ & -0.43 & $-0.61 \sim-0.25$ & $<0.001$ \\
\hline$R^{2}(\mathrm{~A})$ & 0.30 & $0.14 \sim 0.46$ & $<0.001$ & $R^{2}(\mathrm{~A})$ & 0.24 & $0.08 \sim 0.40$ & 0.003 \\
\hline CMJ (C) & & & & $\mathrm{CMJ}(\mathrm{C})$ & & & \\
\hline Direct effects & & & & Direct effects & & & \\
\hline WG $\rightarrow$ SMM (a) & -0.46 & $-0.60 \sim-0.32$ & $<0.001$ & WG $\rightarrow$ SMM (a) & -0.38 & $-0.54 \sim-0.22$ & $<0.001$ \\
\hline $\mathrm{SMM} \rightarrow \mathrm{C}(b)$ & 0.30 & $0.13 \sim 0.47$ & $<0.001$ & $\mathrm{SMM} \rightarrow \mathrm{C}(b)$ & 0.17 & $-0.02 \sim 0.35$ & 0.074 \\
\hline$W G \rightarrow C(c)$ & -0.36 & $-0.52 \sim 0.20$ & $<0.001$ & $W G \rightarrow C(c)$ & -0.34 & $-0.52 \sim-0.16$ & $<0.001$ \\
\hline Indirect effects & & & & Indirect effects & & & \\
\hline$W G \rightarrow C(a \times b)$ & -0.14 & $-0.23 \sim-0.05$ & 0.002 & $W G \rightarrow C(a \times b)$ & -0.06 & $-0.14 \sim 0.01$ & 0.098 \\
\hline Total effect & & & & Total effect & & & \\
\hline$W G \rightarrow C(a \times b+c)$ & -0.50 & $-0.63 \sim-0.36$ & $<0.001$ & $\mathrm{WG} \rightarrow \mathrm{C}(a \times b+c)$ & -0.40 & $-0.56 \sim-0.24$ & $<0.001$ \\
\hline$R^{2}(\mathrm{C})$ & 0.32 & $0.18 \sim 0.46$ & $<0.001$ & $R^{2}(\mathrm{C})$ & 0.18 & $0.04 \sim 0.32$ & 0.007 \\
\hline $5 \mathrm{mSR}(\mathrm{S})$ & & & & $5 \mathrm{mSR}(\mathrm{S})$ & & & \\
\hline Direct effects & & & & Direct effects & & & \\
\hline WG $\rightarrow$ SMM (a) & -0.46 & $-0.60 \sim-0.32$ & $<0.001$ & $\mathrm{WG} \rightarrow \mathrm{SMM}(a)$ & -0.38 & $-0.54 \sim-0.22$ & $<0.001$ \\
\hline $\mathrm{SMM} \rightarrow \mathrm{S}(b)$ & -0.27 & $-0.43 \sim-0.10$ & 0.002 & $\mathrm{SMM} \rightarrow \mathrm{S}(b)$ & -0.30 & $-0.48 \sim-0.12$ & 0.001 \\
\hline $\mathrm{WG} \rightarrow \mathrm{S}(\mathrm{c})$ & 0.37 & $0.21 \sim 0.53$ & $<0.001$ & $\mathrm{WG} \rightarrow \mathrm{S}$ (c) & 0.36 & $0.18 \sim 0.53$ & $<0.001$ \\
\hline Indirect effects & & & & Indirect effects & & & \\
\hline $\mathrm{WG} \rightarrow \mathrm{S}(a \times b)$ & 0.12 & $0.04 \sim 0.21$ & 0.006 & $\mathrm{WG} \rightarrow \mathrm{S}(a \times b)$ & 0.11 & $0.03 \sim 0.20$ & 0.007 \\
\hline Total effect & & & & Total effect & & & \\
\hline $\mathrm{WG} \rightarrow \mathrm{S}(a \times b+c)$ & 0.49 & $0.35 \sim 0.62$ & $<0.001$ & $\mathrm{WG} \rightarrow \mathrm{S}(a \times b+c)$ & 0.47 & $0.32 \sim 0.63$ & $<0.001$ \\
\hline$R^{2}(S)$ & 0.29 & $0.15 \sim 0.43$ & $<0.001$ & $R^{2}(S)$ & 0.30 & $0.14 \sim 0.46$ & $<0.001$ \\
\hline SumPF $\left(S_{P F}\right)$ & & & & SumPF $\left(S_{P F}\right)$ & & & \\
\hline Direct effects & & & & Direct effects & & & \\
\hline WG $\rightarrow$ SMM (a) & -0.46 & $-0.60 \sim-0.32$ & $<0.001$ & WG $\rightarrow$ SMM (a) & -0.38 & $-0.54 \sim-0.22$ & $<0.001$ \\
\hline $\mathrm{SMM} \rightarrow \mathrm{S}_{\mathrm{PF}}(b)$ & 0.32 & $0.16 \sim 0.48$ & $<0.001$ & $\mathrm{SMM} \rightarrow \mathrm{S}_{\mathrm{PF}}(b)$ & 0.34 & $0.17 \sim 0.51$ & $<0.001$ \\
\hline $\mathrm{WG} \rightarrow \mathrm{S}_{\mathrm{PF}}(\mathrm{c})$ & -0.49 & $-0.63 \sim-0.34$ & $<0.001$ & $\mathrm{WG} \rightarrow \mathrm{S}_{\mathrm{PF}}(\mathrm{c})$ & -0.48 & $-0.64 \sim-0.32$ & $<0.001$ \\
\hline Indirect effects & & & & Indirect effects & & & \\
\hline$W G \rightarrow S_{P F}(a \times b)$ & -0.15 & $-0.23 \sim-0.06$ & 0.001 & $W G \rightarrow S_{P F}(a \times b)$ & -0.13 & $-0.21 \sim-0.05$ & 0.003 \\
\hline Total effect & & & & Total effect & & & \\
\hline $\mathrm{WG} \rightarrow \mathrm{S}_{\mathrm{PF}}(a \times b+c)$ & -0.63 & $-0.74 \sim-0.52$ & $<0.001$ & $\mathrm{WG} \rightarrow \mathrm{S}_{\mathrm{PF}}(a \times b+c)$ & -0.61 & $-0.75 \sim-0.47$ & $<0.001$ \\
\hline$R^{2}\left(S_{P F}\right)$ & 0.48 & $0.34 \sim 0.62$ & $<0.001$ & $R^{2}\left(S_{P F}\right)$ & 0.47 & $0.31 \sim 0.63$ & $<0.001$ \\
\hline
\end{tabular}

Abbreviations: WG Weight group, SMM Skeletal muscle mass, CMJ Countermovement jump, $5 \mathrm{mSR} 5 \times 5$-m shuttle run, SumPF Sum of physical fitness score, $95 \% \mathrm{Cl}$ $95 \%$ confidence intervals 
muscle mass and measures of physical fitness. In accordance with our hypotheses, the between-group difference on the sum score of physical fitness, cardiovascular fitness and the $5 \mathrm{mSR}$ test between NWO and NWNO were partially mediated by skeletal muscle mass in both male and female university students. Previous studies have shown that excessive adiposity is associated with lower cardiorespiratory fitness in adults, while skeletal muscle mass is correlated with cardiorespiratory fitness $[21,45]$. Therefore, lower skeletal muscle mass may at least partially account for the poorer physical fitness in students with NWO. The physiological reasoning of our findings may be manifold but have previously been linked to a delayed onset of fatigue due to increased muscle mass and strength [46] as well as an improved central circulation due to an improved venous return [47]. Interestingly, in jumping height a significant partial mediation effect of skeletal muscle mass was observed only in male students. However, while not statistically significant, the direction of the indirect effect of skeletal muscle mass on CMJ was similar in female students; in fact it was less than 0.1 and pointed to the same direction as in men. Therefore, the present analysis should be reproduced in a larger sample to validate whether in fact the paths are actually similar in both genders. Taken together, skeletal muscle mass is a mediator for the physical fitness in students with normal weight but high fat mass.

When interpreting the present findings, some strengths and limitations need to be considered. The classifications of NWO were based on Chinese-specific cut-off points for BMI, which increases the generalizability and comparability of the findings to the Chinese population but not necessarily to other nations. In addition to analyzing the relationship between NWO and physical fitness, we further performed a mediation analysis to clarify whether or not the observed relationships are explained by the differences in skeletal muscle mass. However, one should bear in mind that the cross-sectional design of the study does only allow to draw associations but not causalities [48]. Thus, longitudinal studies are needed to confirm the observed direction of the relationship between body composition and physical fitness. In addition, while using muscle mass as a mediator is well justified based on previous studies [20-22], we recommend to utilize precise measures of physical activity (e.g. objectively assessed physical activity) in future studies in order to clarify the role of physical activity in NWO. Last, the study population included only university students. While this is an important population to study, further investigations are needed to confirm the findings in broader age groups. Despite these limitations, the results are of relevance because so far only few studies have yet examined the effects of physical fitness in relation to normal weight obesity.

\section{Conclusion}

This study showed that $13.7 \%$ of male and $27.5 \%$ of female students were classified as NWO and these students were characterized by lower levels of physical fitness than their NWNO peers. The low levels of physical fitness in NWO were partially explained by a lower skeletal muscle mass in both males and females. The findings indicated that much attention should be paid for the potential hidden health risk in university students with normal body mass index but excessive fat mass.

\section{Additional file}

Additional file 1: Participants characteristics stratified by gender and four weight group. (PDF 129 kb)

\section{Abbreviations}

BMI: Body mass index; NWO: Normal weight obesity; NWNO: Normal weight non-obese; BH: Body height; BW: Body weight; WC: Waist circumference; VFA: Visceral fat area; Fat\%: Body fat percentage; SMM: Skeletal muscle mass; DBP: Diastolic blood pressure; SBP: Systolic blood pressure; HR: Heart rate; PA: Physical activity; WG: Weight group; SMM: Skeletal muscle mass; CMJ: Countermovement jump; $5 \mathrm{mSR}: 5 \times 5 \mathrm{~m}$ shuttle run; SumPF: Sum of physical fitness score; $95 \% \mathrm{Cl}$ : 95\% confidence intervals

\section{Acknowledgements \\ The authors would like to thank the participants for taking part in the study and study funding agencies. \\ Funding \\ This study was supported by China Postdoctoral Science Foundation (grant no. 2016 M591657), Humanities and Social Sciences Project of the Ministry of Education of China (grant no. 18YJA890034), Academy of Finland grant (grant no. 286536) and Youth Foundation of Taiyuan University of Technology (grant no. 2016RS14). \\ The funding bodies have no role in the design of the study and collection, analysis, and interpretation of data and in writing the manuscript.}

\section{Availability of data and materials}

The dataset generated during the current study is available from the corresponding and first authors upon request.

\section{Authors' contributions}

MZ, TH, MS and SC contributed to the study concept and design. MZ collected the data and analyzed the results. $\Pi, M Z$ and $\mathrm{TH}$ contributed the interpretation of the study. MZ, MS, TH and SC contributed to the preparation and revision of manuscript. All authors read and approved the final manuscript.

\section{Ethics approval and consent to participate}

All participants provided written informed consents prior to the tests. The consent form and ethical research procedures was approved by the Institutional Review Board of Shanghai Jiao Tong University (M15018).

\section{Consent for publication}

This manuscript does not contain individual level data and thus this is not relevant.

\section{Competing interests}

The authors declare that they have no competing interests.

\section{Publisher's Note}

Springer Nature remains neutral with regard to jurisdictional claims in published maps and institutional affiliations. 


\section{Author details}

'Department of Physical Education, Exercise, Health and Technology Centre, Shanghai Jiao Tong University, Shanghai 200240, China. ${ }^{2}$ College of Physical Education, Taiyuan University of Technology, Taiyuan, Shanxi, China. ${ }^{3}$ School of Life Sciences and Biotechnology, Shanghai Jiao Tong University, Shanghai 200240, China. ${ }^{4}$ Department of Molecular and Cellular Sports Medicine, German Sport University, Cologne, Germany. ${ }^{5}$ Gerontology Research Center, Faculty of Sport and Health Sciences, University of Jyväskylä, Jyväskylä, Finland. ${ }^{6}$ The Key Laboratory of Systems Biomedicine, Ministry of Education, and Exercise Translational Medicine Center, Shanghai Center for Systems Biomedicine, Shanghai Jiao Tong University, Shanghai, China. 'Faculty of Sport and Health Sciences, University of Jyväskylä, Jyväskylä, Finland.

\section{Received: 11 March 2018 Accepted: 20 November 2018} Published online: 04 December 2018

\section{References}

1. Aballay LR, Eynard AR, Diaz Mdel P, Navarro A, Munoz SE. Overweight and obesity: a review of their relationship to metabolic syndrome, cardiovascular disease, and cancer in South America. Nutr Rev. 2013;71:168-79.

2. Pi-Sunyer FX. The obesity epidemic: pathophysiology and consequences of obesity. Obes Res. 2002;10(Suppl 2):97S-104S

3. Poirier PGT, Bray GA, Bray GA, Hong Y, Stern JS, Pi-Sunyer FX, Eckel RH. Obesity and cardiovascular disease: pathophysiology, evaluation, and effect of weight loss. Circulation. 2006;113:898-918.

4. Jiang S, Peng S, Yang T, Cottrell RR, Li L. Overweight and obesity among Chinese college students: an exploration of gender as related to external environmental influences. Am J Mens Health. 2018;12:926-34.

5. Tian $Y$, Jiang C, Wang M, Cai R, Zhang $Y$, He Z, Wang H, Wu D, Wang F, Liu $X$, et al. BMI, leisure-time physical activity, and physical fitness in adults in China: results from a series of national surveys, 2000-14. Lancet Diabetes Endocrinol. 2016;4:487-97.

6. World Health Organization. Obesity: preventing and managing the global epidemic. Report of a WHO consultation, vol. 894: World Health Organization technical report series; 2000. p. i-xii. 1-253

7. Javed A, Jumean M, Murad MH, Okorodudu D, Kumar S, Somers VK, Sochor O, Lopez-Jimenez F. Diagnostic performance of body mass index to identify obesity as defined by body adiposity in children and adolescents: a systematic review and meta-analysis. Pediatr Obes. 2015;10:234-44.

8. Flegal KM, Carroll MD, Kit BK, Ogden CL. Prevalence of obesity and trends in the distribution of body mass index among US adults, 1999-2010. JAMA 2012:307:491-7.

9. Okorodudu DO, Jumean MF, Montori VM, Romero-Corral A, Somers VK, Erwin PJ, Lopez-Jimenez F. Diagnostic performance of body mass index to identify obesity as defined by body adiposity: a systematic review and meta-analysis. Int J Obes (Lond). 2010:34:791-9.

10. Kennedy AP, Shea JL, Sun G. Comparison of the classification of obesity by BMI vs. dual-energy X-ray absorptiometry in the Newfoundland population. Obesity (Silver Spring). 2009;17:2094-9.

11. Romerocorral A, Somers VK, Sierrajohnson J, Thomas RJ, Bailey KR, Collazoclavell ML, Allison TG, Korinek J, Batsis JA, Lopezjimenez F. Accuracy of body mass index to diagnose obesity in the us adult population. Int J Obes. 2008;32:959-66.

12. Oliveros E, Somers VK, Sochor O, Goel K, Lopez-Jimenez F. The concept of normal weight obesity. Prog Cardiovasc Dis. 2014:56:426-33.

13. Romero-Corral A, Montori VM, Somers VK, Korinek J, Thomas RJ, Allison TG Mookadam F, Lopez-Jimenez F. Association of bodyweight with total mortality and with cardiovascular events in coronary artery disease: a systematic review of cohort studies. Lancet. 2006;368:666-78.

14. Adamu B, Sani MU, Abdu A. Physical exercise and health: a review. Niger J Med. 2006;15:190-6.

15. Ekelund U, Steene-Johannessen J, Brown WJ, Fagerland MW, Owen N, Powell KE, Bauman A, Lee IM. Does physical activity attenuate, or even eliminate, the detrimental association of sitting time with mortality? A harmonised meta-analysis of data from more than 1 million men and women. Lancet. 2016;388:1302-10.

16. Bonney E, Ferguson G, Smits-Engelsman B. Relationship between Body Mass Index, Cardiorespiratory and Musculoskeletal Fitness among South African Adolescent Girls. Int J Environ Res Public Health. 2018;15. pii: E1087. https:// doi.org/10.3390/ijerph15061087.

17. Diez-Fernandez A, Sanchez-Lopez M, Gulias-Gonzalez R, Notario-Pacheco B, Canete Garcia-Prieto J, Arias-Palencia N, Martinez-Vizcaino V. BMI as a mediator of the relationship between muscular fitness and cardiometabolic risk in children: a mediation analysis. PLoS One. 2015;10:e0116506. https:// doi.org/10.1371/journal.pone.0116506.

18. Lopes VP, Malina RM, Gomez-Campos R, Cossio-Bolanos M, Arruda M, Hobold E. Body mass index and physical fitness in Brazilian adolescents. J Pediatr (Rio J). 2018. pii: S0021-7557(17)31024-0. https://doi.org/10.1016/j. jped.2018.04.003.

19. Nichols S, O'Doherty AF, Taylor C, Clark AL, Carroll S, Ingle L. Low skeletal muscle mass is associated with low aerobic capacity and increased mortality risk in patients with coronary heart disease - a CARE CR study. Clin Physiol Funct Imaging. 2018. https://doi.org/10.1111/cpf.12539 [Epub ahead of print].

20. Vaara JP, Kyrolainen H, Niemi J, Ohrankammen O, Hakkinen A, Kocay S, Hakkinen K. Associations of maximal strength and muscular endurance test scores with cardiorespiratory fitness and body composition. J Strength Cond Res. 2012;26:2078-86.

21. Flouris AD, Metsios GS, Koutedakis Y. Contribution of muscular strength in cardiorespiratory fitness tests. J Sports Med Phys Fitness. 2006;46:197-201.

22. Rodriguez Valero FJ, Gualteros JA, Torres JA, Umbarila Espinosa LM, RamirezVelez R. Association between muscular fitness and physical health status among children and adolescents from bogota, Colombia. Nutr Hosp. 2015; 32:1559-66.

23. Ogawa H, Fujitani K, Tsujinaka T, Imanishi K, Shirakata H, Kantani A, Hirao M, Kurokawa Y, Utsumi S. InBody 720 as a new method of evaluating visceral obesity. Hepato-Gastroenterology. 2011;58:42-4

24. Volgyi E, Tylavsky FA, Lyytikainen A, Suominen H, Alen M, Cheng S. Assessing body composition with DXA and bioimpedance: effects of obesity, physical activity, and age. Obesity (Silver Spring). 2008;16:700-5.

25. Zhou BF, Cooperative meta-analysis Group of the Working Group on obesity in C. Predictive values of body mass index and waist circumference for risk factors of certain related diseases in Chinese adults--study on optimal cut-off points of body mass index and waist circumference in Chinese adults. Biomed Environ Sci. 2002;15:83-96.

26. Jacobs DR Jr, Ainsworth BE, Hartman TJ, Leon AS. A simultaneous evaluation of 10 commonly used physical activity questionnaires. Med Sci Sports Exerc. 1993;25:81-91.

27. Andersen LB, Andersen TE, Andersen E, Anderssen SA. An intermittent running test to estimate maximal oxygen uptake: the Andersen test. J Sports Med Phys Fitness. 2008:48:434-7.

28. Klavora P. Vertical-jump tests: a critical review. Strength Cond J. 2000;22:70.

29. Markovic G, Dizdar D, Jukic I, Cardinale M. Reliability and factorial validity of squat and countermovement jump tests. J Strength Cond Res. 2004;18:551-5.

30. Ruiz JR, Ortega FB, Gutierrez A, Meusel D, Sjöström M, Castillo MJ. Healthrelated fitness assessment in childhood and adolescence: a European approach based on the AVENA, EYHS and HELENA studies. J Public Health (Oxf). 2006;14:269-77.

31. Boddington MK, Lambert MI, St CGA, Noakes TD. Reliability of a 5-m multiple shuttle test. J Sports Sci. 2001:19:223.

32. Andersen LB, Harro M, Sardinha LB, Froberg K, Ekelund U, Brage S, Anderssen SA. Physical activity and clustered cardiovascular risk in children: a cross-sectional study (the European youth heart study). Lancet. 2006;368: 299-304.

33. Lima RA, Larsen LR, Bugge A, Andersen LB. Physical fitness is longitudinally associated with academic performance during childhood and adolescence, and waist circumference mediated the relationship. Pediatr Exerc Sci. 2018;30:317-25.

34. Imai K, Keele L, Tingley D. A general approach to causal mediation analysis. Psychol Methods. 2010;15:309-34.

35. Loeys T, Moerkerke B, Vansteelandt S. A cautionary note on the power of the test for the indirect effect in mediation analysis. Front Psychol. 2015;12:1549.

36. Rucker DD, Preacher KJ, Tormala ZL, Petty RE. Mediation analysis in social psychology: current practices and new recommendations. Soc Personal Psychol Compass. 2011;5:359-71.

37. Marques-Vidal P, Pecoud A, Hayoz D, Paccaud F, Mooser V, Waeber G, Vollenweider P. Normal weight obesity: relationship with lipids, glycaemic status, liver enzymes and inflammation. Nutrition, metabolism, and cardiovascular diseases. Nutr Metab Cardiovasc Dis. 2010;20:669-75.

38. Wiklund $P$, Tormakangas T, Shi Y, Wu N, Vainionpaa A, Alen M, Cheng S. Normalweight obesity and cardiometabolic risk: a 7-year longitudinal study in girls from prepuberty to early adulthood. Obesity (Silver Spring). 2017;25:1077-82.

39. Cheng S, Wiklund $P$. The effects of muscle mass and muscle quality on cardio-metabolic risk in peripubertal girls: a longitudinal study from childhood to early adulthood. Int J Obes. 2017;42:648-54. 
40. Owolabi EO, Ter Goon D, Adeniyi OV. Central obesity and normal-weight central obesity among adults attending healthcare facilities in Buffalo City metropolitan municipality, South Africa: a cross-sectional study. J Health Popul Nutr. 2017:36:54

41. Gomez-Ambrosi J, Silva C, Galofre JC, Escalada J, Santos S, Millan D, Vila N, Ibanez P, Gil MJ, Valenti $V$, et al. Body mass index classification misses subjects with increased cardiometabolic risk factors related to elevated adiposity. Int J Obes (Lond). 2012;36:286-94.

42. Madeira FB, Silva AA, Veloso HF, Goldani MZ, Kac G, Cardoso VC, Bettiol H, Barbieri MA. Normal weight obesity is associated with metabolic syndrome and insulin resistance in young adults from a middle-income country. PLoS One. 2013;8:e60673. https://doi.org/10.1371/journal.pone.0060673.

43. Romero-Corral A, Somers VK, Sierra-Johnson J, Korenfeld Y, Boarin S, Korinek J, Jensen MD, Parati G, Lopez-Jimenez F. Normal weight obesity: a risk factor for cardiometabolic dysregulation and cardiovascular mortality. Eur Heart J. 2010;31:737-46.

44. Ekelund LG, Haskell WL, Johnson JL, Whaley FS, Criqui MH, Sheps DS. Physical fitness as a predictor of cardiovascular mortality in asymptomatic north American men. The lipid research clinics mortality follow-up study. N Engl J Med. 1988;319:1379-84.

45. Kim TN, Park MS, Kim YJ, Lee EJ, Kim MK, Kim JM, Ko KS, Rhee BD, Won JC. Association of low muscle mass and combined low muscle mass and visceral obesity with low cardiorespiratory fitness. PLoS One. 2014;9:e100118. https://doi.org/10.1371/journal.pone.0100118.

46. de Oliveira RJ, Bottaro M, Motta AM, Pitanga F, Guido M, Leite TK, Bezerra LM, Lima RM. Association between sarcopenia-related phenotypes and aerobic capacity indexes of older women. J Sports Sci Med. 2009;8:337-43.

47. Hunt BE, Davy KP, Jones PP, DeSouza CA, Van Pelt RE, Tanaka H, Seals DR. Role of central circulatory factors in the fat-free mass-maximal aerobic capacity relation across age. Am J Phys. 1998;275:H1178-82.

48. Maxwell SE, Cole DA, Mitchell MA. Bias in cross-sectional analyses of longitudinal mediation: partial and complete mediation under an autoregressive model. Multivar Behav Res. 2011;46:816-41.

Ready to submit your research? Choose BMC and benefit from:

- fast, convenient online submission

- thorough peer review by experienced researchers in your field

- rapid publication on acceptance

- support for research data, including large and complex data types

- gold Open Access which fosters wider collaboration and increased citations

- maximum visibility for your research: over $100 \mathrm{M}$ website views per year

At $\mathrm{BMC}$, research is always in progress.

Learn more biomedcentral.com/submissions 